Noname manuscript No.

(will be inserted by the editor)

\title{
COVID-19: Energy landscape theory of SARS-CoV-2 complexes with Particulate Matter.
}

\author{
Gianluigi Zangari del Balzo
}

Received: date / Accepted: date

\begin{abstract}
In the fight against the COVID-19 pandemic, the thermodynamics of the novel SARS-CoV-2 coronavirus has been overlooked and, therefore, much is still unknown. Hence there is a serious methodological problem which, if not addressed and solved, can invalidate the results of the entire research and prophylaxis.

In particular, most of the structural and functional models of the novel SARSCoV-2 coronavirus lack a correct definition of the thermodynamics of the viral particle with its environment. This is a serious systematic error.

In the present work we therefore study the thermodynamics of SARS-CoV-2 in its "hunting" environment, from air transport to cellular entry into the host. The first fundamental point is that in the study of the thermodynamics of the air environment of SARS-CoV-2, the presence of nanoparticles, dust, pollutants and other particles of an order of magnitude at least comparable to that of the viral particle cannot be overlooked.

This work therefore starts from a comparative study of the environments in China and Italy, the first countries affected by the infection. When the present study started (February 2020) there was still no evidence of a correlation between the spread of infection and pollution, but today there is much experimental evidence of this. Indeed, many studies agree that the countries most affected by the pandemic are also the most polluted. Apart from the initial case of China and Italy, we have thus evidence of this correlation in other countries hard hit by the pandemic such as the United States, Mexico, the United Kingdom, Brazil and others.
\end{abstract}

Gianluigi Zangari del Balzo

Sapienza University of Rome

E-mail: gianluigi.zangaridelbalzo@gmail.com 
We therefore propose a theory of the energy landscape of the cooperative and synergistic complexes that the new coronavirus SARS-CoV-2 forms with particulate dust and other pollutants.

This model explains both the effects of the selective pressure exerted by the environment on the parasite, and the emergence of devastating viral quasi-species, tracing in a single formalism the main variables and parameters that describe the formation of synergistic and cooperative complexes of SARS-CoV- 2 with the particles present in the environment.

It explains in particular why the complexification of the parasite due to the environmental selective pressure in the environment is not only necessary for its survival and reproductive strategy, but at the same time has a devastating effect for the host species.

Ultimately, on the basis of this model it is therefore possible:

1) on the one hand to explain the thermodynamics of the phenomenon to avoid the onset of dangerous systematic errors

2) on the other to devise new research tools and methods to study the evolution and spread of infection

3 ) at the same time, making any improvements to vaccine prophylaxis, focusing research on the most dangerous viral quasi-species, saving time, resources and costs for the companies that produce the vaccines.

\section{Pandemic COVID-19}

The pandemic caused by the new coronavirus SARS-CoV-2 appeared in Wuhan, the capital of the Chinese province of Hubei, in December 2019.

Immediately after China, SARS-CoV-2 infection hit Italy hard, causing thousands of victims to date.

At the beginning of last March 2020 a report by World Wildlife Fund (WWF) Italy "Pandemics and the boomerang effect of the destruction of ecosystems" Pratesi et al. (2020) aroused my curiosity because it proposed a connection between two apparently unrelated topics: "ecology and pandemics". On the same issues, but from another point of view, an interesting video was published on March 20 by the climate change scientist Antonello Pasini at the Italian National Research Council -CNR where it was speculated on a (impossible) cause-effect relationship between climate change and SARS-CoV-2 infection Pasini A and Italian National Research Council -CNR (2020).

So, both the WWF report and the CNR video discussed an impossible correlation between environmental damage (pollution, climate change) and the pandemic. In any case, the topic immediately aroused my interest as a theoretical physicist and since the end 
of February 2020, I was wondering in the first place how the novel SARS-CoV-2 coronavirus could be directly affected by the environment.

The first step was therefore to study the thermodynamic characterization of the virus in the environment.

The next step was to believe that in the study of the thermodynamic environment in the air of the SARS-CoV-2 virus, the presence of nanoparticles, dust and other particles, at least in the order of magnitude comparable to that of the viral particle, could not be neglected.

This also applies to simulations. Otherwise, we run into serious systematic errors.

The result of these observations was the model of the energy landscape proposed here.

At the beginning of March 2020 I published my work as a preprint, wishing to immediately make my observations available to the community of colleagues, operators in the sector, doctors, journalists and social networkers and at the same time sent to the authorities of the Italian Government.

I am truly happy and grateful to the many colleagues and research institutes who have used and confirmed my concerns and assumptions, showing the association between air pollution and infection. Among these I would like to mention the position paper of the Italian Society of Environmental Medicine (SIMA) issued on March 16, 2020 and the first results of a survey conducted in the United States by the Harvard School of Public Health Wu, X., Nethery, RC, Sabath, MB , Braun, D. and Dominici, F. (2020)

\section{China and Italy}

Let's start on China and Italy the two nations tragically hit first by the epidemic. In the Chinese case, I will focus on Wuhan, the capital of Hubei Province, while in the Italian case I will focus on Northern Italy, with particular attention to the case of Lombardia. As an example, Lombardia have roughly the same population (about 10 million people) The Government of Wuhan (2020); Setti L et al (2020); Regione Lombardia (2020). Both have been affected by the pandemic in the most devastating way. Both have suffered a severe environmental pollution situation in recent years, China with greater severity and impact on the health of population Wang et al. (2019); CHINA National Environmental Monitoring Centre - CNEMC (2020); Rongshan Wu et al. (2018); Rohde and Muller (2015); Mike Z He et al. (2017); Dan Liang et al. (2019); Zhao et al. (2018); Liu et al. (2017); Anenberg et al. (2019); Yanhong Zhu et al. (2018); Kuerban et al. (2020); Zhang and Cao (2015); Xu et al. (2020); Ren et al. (2017), WU, Xiao et al (2020). Most papers analyze data from Chinese government agencies, as Wang et al. (2019), which refers to the Chinese Ministry of the Environment and Ecology, where we find the latest (2017) report of Ecology Ministry of Ecology of the People's Republic of China (2017) translated in English (See figures 1 and 2).

[Fig. 1 about here.]

[Fig. 2 about here.]

The Italian situation is summarized by the European Environment Agency (See Figure 3-4 European Environment Agency (2019-2020) )

[Fig. 3 about here.]

Note that the highest values of Particulate Matter are reached in the regions of Northern Italy (See Fig. 4), the same regions hit by the pandemic (!) (See fig. 5).

[Fig. 4 about here.]

[Fig. 5 about here.] 


\section{Particulate Matter}

The definition of particulate matter (hereinafter referred to as "PM") and its health effects are well-known. We recall the definition given by the U.S. Environmental Protection Agency (EPA) United States Environmental Protection Agency - EPA (2020) : PM is a mixture of solid particles and liquid droplets in air.

We then have:

$\mathbf{P M}_{10}$ : particles, with diameters that are generally $10 \mu \mathrm{m}$ and smaller.

$\mathbf{P M}_{2.5}$ : fine particles, with diameters that are generally $2.5 \mu \mathrm{m}$ and smaller.

Ultrafine particulate (UFPs) are defined as "respirable dust", that is, capable of penetrating deeply into the lungs and undergo interstitialisation, Friedlander et al. (2003)

We then have:

PM1, with a diameter of less than $1 \mu \mathrm{m}$;

PMo.1, with a diameter of less than $0.1 \mu \mathrm{m}$.

The health effects of PM are devastating, particularly in the lungs. $\mathrm{PM}_{2.5}$ is a thoracic powder capable of penetrating deeply into the lungs during breathing, while the ultrafine particulate matter (UFPs) is in all respects a "respirable dust", which settles in the lungs, where the nano-particles have the ability to penetrate the tissues and undergo interstitialisation or to be absorbed directly into the bloodstream Friedlander et al. (2003); Scientific Committee on Emerging and Newly Identified Health Risks -SCENIHR (2006); Scientific Committee on Health and Environmental Risks - SCHER (2005); European Environmental Agency (2019); Xing et al. (2016); MacNee et al. (2003). The studies on the damage caused by PM on the respiratory system generally take into account free radical peroxidation, imbalanced calcium homeostasis, inflammatory lesions etc. In particular, the peroxidation of free radicals is one of the main factors causing oxidative DNA damage. Indeed, when damaged DNA is not repaired effectively over time, it can induce carcinogenesis, mutagenesis, and other irreversible damage SCHER (2005); European Environment Agency (2019); Xing et al. (2016); MacNee et al. (2003) . Moreover, oxidative stress within cells is an additional factor leading to transcription of pro-inflammatory genes Xing et al. (2016); MacNee et al. (2003) .

\section{SARS-CoV-2}

SARS-CoV-2 virus is a beta-coronavirus as SARS-CoV; its RNA genome is about $82 \%$ identical to the SARS-CoV Zhang et al. (2020) . SARS-CoV-2 has round or elliptic and often pleomorphic form, and a diameter of circa 60$140 \mathrm{~nm}$ Cascella et al. (2020). Angiotensin converting enzyme 2 (ACE2) is the cell receptor for both the SARS-CoV and the new SARS-CoV-2 Yan et al. (2020) . Now we know the X-ray structures of the unliganded SARS-CoV$2 \mathrm{M}^{\text {pro }}$ and its complex with an $\alpha$-ketoamide inhibitor Zhang et al. (2020) and many other features. As virus SARS-CoV, the new virus SARS-CoV-2 also enters cells through an endocytic pathway Hongliang Wang et al. (2008), 
as has recently been confirmed by many studies such as an interesting "snapshot" of COVID-19 by Blake Oberfield et Al. (Harvard Medical School and MIT) Oberfield et al. (2020), by Alexandra C. Walls et Al. (Washington University, Seattle, USA), Walls et al. (2020) and many others. With each passing day, new details emerge. We acknowledge the excellent actions promoted by CERN community such as "CERN against Covid-19" CERN, Genève, CH (2020a), "Zenodo" (Open Science against COVID-19, which I also adhere to) CERN, Genève, CH (2020c), and the platform folding@home , which is a distributed computing project for simulating the dynamics of protein molecules CERN, Genève, CH (2020b).

Finally, I remember the very updated report of the Covid-19 Commission of the Accademia Nazionale dei Lincei, directed by Prof. Giorgio Parisi Accademia Nazionale dei Lincei (2021).

In the following figure, courtesy of N.J. Dimmock Dimmock et al. (2016), we recall the main processes of entry of animal viruses genomes into cells.

[Fig. 6 about here.]

In the present case, SARS-CoV-2 will exploit the process (b) of the previous figure 5 (receptor-mediated endocytosis). Thus, SARS-CoV-2 is an enveloped virus that enters the cell in a vesicle (endocytosis). The vesicle subsequently merges with an endosome. The low $\mathrm{pH}$ environment inside the endosome promotes conformational changes in viral proteins that lead to the fusion of the lipid bilayer of the virus with the endosome allowing the viral genome and its associated proteins to enter the cytoplasm.

This is the big picture. However, in our case, things are a bit more bizarre and require a more advanced formalism

\section{4 - SARS-CoV-2 and Particulate Matter}

However, the generally accepted description of endocytosis, which we also find in the text by Dimmock et al. (2016) is wrong because nothing is specified about the environment, as if a viral particle (as well as a protein, as well as any living organism or part of a living organism) could exist without its environment, in a vacuum (nihil sine causa datum est). This is a serious systematic error.

Let's consider therefore the new coronavirus in its environment.

Consider a given concentration of viral particles per unit of air volume. As an example, among the many works, including Italian ones, we choose a recent article from Yuan Liu et Al.(2020), from Wuhan, about the concentration of different aerodynamic dimensions of SARS-CoV-2 aerosols in Wuhan hospitals during the lock-down, so as not to overestimate the concentrations.

Consider thus a spherical neighborhood (ball) $\mathcal{B}(r)$ of radius $r>0$ around a viral particle such that $\mathrm{r}_{0}<\mathrm{r}<\mathrm{pr}_{0}$ where $\mathrm{r}_{\mathrm{o}}$ is the average diameter of a viral particle and $p=1, \ldots, L \in N$, where $L$ is the side of a cubic box with a volume of $1 \mu \mathrm{m}^{3}$. For each $\mathrm{p}>0$ there will be a ball $\mathcal{B}(r)$ in which a number

$\mathrm{N} \neq 0$ of $\mathrm{PM}$ (particulate matter ) particles will fall. 
The following figure 7 shows a snapshot of a possible scenario of the ball (SARS-CoV-2 with the environment) for a low density of the UFP dust from $0.025 \mu \mathrm{m}$ to $0.100 \mu \mathrm{m}$.

[Fig. 7 about here.]

As shown in Figure 8 below, the endocytosis process captures the entire ball containing the virus with its micro-environment inside a vesicle, deforming the ball shape into an "ellipsoid". (see fig. 8).

[Fig. 8 about here.]

From the moment the endocytosis process takes place and the whole ball is incorporated into the vesicle, a thermodynamic isolated system is created (See figure 9).

[Fig. 9 about here.]

\section{5- A synergistic cooperation between SARS-CoV-2 and Particulate Matter.}

We see below how important it is to consider and study the environment where the parasite combines with the host. Conversely, neglect of the environment leads to serious systematic errors throughout the pandemic COVID-19 research chain.

Consider that the new coronavirus SARS-CoV-2 is an obligate parasite and our species is its host, that is, the virus needs us to be able to replicate itself. Therefore the survival of our species cannot be questioned, as we are the very welcome (for us very unwelcome) hosts of the virus, Dimmock NJ et al (2016). So we can assume that the interaction of the viral particles with us will result in a necessary mutual adaptation - possibly long and very troubled for us - for the following reasons:

1) First of all it is clear that the parasite will have to adapt to the host (us) and to the environment where the host lives, that is the air environment with the presence of particulate dust and other pollutants, especially in the most industrialized and populous areas of the planet (where in fact the pandemic began and has thrived);

2) Second, it is equally clear that the host (our species) will have to adapt to the new parasite in our common living environment, that is the air environment with the presence of particulates and other pollutants.

In the present case, the SARS-CoV-2 parasite was probably already well adapted to our environment when it started hunting us. That is, he has found his ideal host in his hunting ground.

For the parasite, adaptation to the host's environment has obvious consequences in its attack strategies on the host cell. For the host, adaptation to the parasite has serious consequences on its ability to survive and resist the parasite's attack, which it will have to memorize and pass on to subsequent generations. It is very likely that the encounter with this devastating and dangerous parasite results in a significant evolutionary forcing of our species.

Neglecting for the moment the evolutionary forcing that will result for our species - a problem that must be carefully analyzed and evaluated - let's focus on the parasite's attack strategies in its hunting environment, where the host lives.

The adaptation of the parasite to the host's environment obviously conditions its attack strategy also at the molecular level. The parasite will specialize in exploiting the atmospheric environment to its advantage with the presence of particles, dust and pollutants, in particular at the densities of the most polluted 
areas of the planet where, as we have seen, the pandemic was and unfortunately is more aggressive and lethal.

To get an idea of how the parasite evolved and specialized in exploiting the host's environment to its advantage, let's consider the equivalent in the form of human technology. One might think that the parasite is able to intelligently exploit the conditions and peculiarities of the environment to its own exclusive advantage. In fact, the strategy employed goes far beyond the human technological capabilities in the field of so-called nanotechnologies, which the parasite uses in an extraordinarily efficient way. Let's see what it is.

Much human research on nanotechnologies has sought to exploit the ability of certain compounds such as mesoporous silica nanomaterials (MSNs) to penetrate human cells through endocytosis, to perform intracellular detection and monitoring functions or to release genetic material or drugs inside of the cell Brian G Trewyn et al. (2008).

In our case, the process of endocytosis with nanoparticles is spontaneously performed by the parasite through a complex $[S A R S-\operatorname{CoV}-2] \oplus[P M]$, with extraordinary efficacy, far exceeding human capabilities in the field of nanotechnology. As usual there is only to learn from Nature.

While for the parasite, the use of a particle carrier such as particulate matter increases the efficiency of its cell attack and entry, for the host it is a devastating impact. In fact, from the host's point of view, the [SARS-CoV-2] $\oplus[\mathrm{PM}]$ complex is a devastating lethal weapon not only because it introduces lethal poisons into cells, weakening the organism and irreparably damaging cellular structures and architectures (i.e. the pulmonary interstices), but also because it exploits the ability of the particulate dust to promptly alter molecular structures and functions and induce genetic modifications. In the end, it is as if the guest is being bombed by a "smart bomb".

In order to achieve this goal, [SARS - CoV - 2] $\bigoplus[P M]$ complexes must be minimal entropy, close packed, highly cooperative and synergistic structures. In this way, the viral protein structures of the new coronavirus will strictly interact with the particulate dust. Since the system is isolated inside a vesicle, the thermodynamic universe (See figure 9), all the interaction processes (mechanical-thermal-chemical) between the viral particle and the particulate dust will go to thermodynamic equilibrium, thus stabilizing the complex in a synergistic cooperative single entity.

For the host the complexes $[S A R S-\operatorname{CoV}-2] \oplus[P M]$ thus achieve a synergistic and highly cooperative smart optimization of the cell demolition strategies, which 
exceed the individual potentials of both viral and particulate particles, as soon as they are considered as independent forcing agents on the host cell.

The presence of multiple non-covalent interactions between SARS-CoV-2 and PM is a source of cooperativity between them. When these interactions cooperate is a stable single conformation produced, that of the complex $[S A R S-\mathrm{CoV}-2] \oplus[P M]$. The complex created is therefore much stronger than might be expected from the sum of their individual strengths.

This can explain the rapid spread of the pandemic in the areas of the greatest pollution.

This exceptional cooperative optimization can also explain the severity and difficulty of treating the forms of interstitial pneumonia that occur in Italy and worldwide.

But not only that, it could perhaps also help us understand the ratio legis that determines the selective pressure of the air environment with pollutants on SARS-CoV-2 mutations that worry the global scientific community and make prophylaxis difficult.

Let's see from the theoretical point of view how the complex formation mechanism can be represented and described by a mathematical model.

\section{The energy landscape of $[\mathrm{SARS}-\mathrm{CoV}-2] \oplus[\mathrm{PMs}]$ complexes.}

The theoretical structure that is the most appropriate to describe the complexes $[S A R S-\mathrm{CoV}-2] \oplus[P M]$ is that of the "rugged funnel" energy landscape by Hans Frauenfelder and Peter G Wolynes Frauenfelder (2005); Frauenfelder et al. (1991); Frauenfelder (1997); Wolynes and Luthey-Schulten (1997).

Molecular biophysical interactions between viral particles and PM dust are mediated by SARS-CoV-2 proteins (e.g. spike proteins), therefore the energy rugged funnel is certainly the best possible model.

\section{Postulate 1. Rugged Energy Landscapes.}

The energy landscapes of SARS-CoV-2 and PM dust are rugged due to the possibility of continuous contacts and interactions, among which we consider the non-covalent interactions that combine cooperatively to create complexes. We call them "complex- interactions". When non-complex interactions are made, the energy contributions are random.

\section{Postulate 2. The "principle of minimal frustration".}

The rugged landscapes are not globally flat but have a preferred direction of flow. There is an overall regular slope of the energy landscape, which is a symptom of cooperativity and synergy: the interactions and conformational energies between SARS-CoV-2 and PM dust are highly stabilizing, until reaching the minimum of entropy.

Consider therefore the rugged funnel landscape diagram in the following figure 10 .

[Fig. 10 about here.] 
We introduce the order parameter "Q" as the percentage of complex-like interactions between SARS-CoV-2 and PM dust, according to the different size and density of PMs (as an example, in the scenario of the previous section, we considered a med-hi density for three dust sizes, from $0.025 \mu \mathrm{m}$ to $0.100 \mu \mathrm{m}$ ).

The functional dependence of the thermal average energy will be $\bar{E}(Q)$, the ruggedness will be $\sqrt{\Delta E^{2}(Q)}$; the density of states will be $\Omega(E, Q)$; the entropy will be $S(E, Q)$ and the local glass transition temperature will be $T_{g}(Q)$.

In the "ball" stages, as the interaction between the viral particles and dust are random $(\mathrm{Q} \approx 0)$ there will be many states and the ensemble average is most appropriate. The hopping rate $\mathrm{R}$ between micro-states at each stage is

$$
R \approx e^{-\Delta E^{2} / k_{B} T^{2}}
$$

Where $\mathrm{k}_{B}$ is the Boltzmann constant and $\mathrm{T}$ the absolute temperature.

The probability distribution of energies in the interval $\delta E$ at any position in the funnel is a Gaussian centered about the mean energy

$$
P(E) \delta E=\frac{1}{\sqrt{2 \pi \Delta E^{2}(Q)}} \exp \left\{-\frac{(E-\bar{E}(Q))^{2}}{2 \Delta E^{2}(Q)}\right\} \delta E
$$

Now we will define the configuration space.

Consider a spike protein of SARS-CoV-2. If we consider $\gamma$ dust configurations per spike in the ball state $(\mathrm{Q} \approx 0)$, then the total number of configurations for a viral particle with $\mathrm{N}$ spikes will be $\Omega_{0}(Q)=\gamma^{N}$.

When the system approaches the state of the complexes, the number of configurations will decrease, until the only configurations will be those of the complexes $(\mathrm{Q} \approx 1)$.

If $\Omega_{0}(Q)$ is the number of structures that have a fraction $Q$ of the contacts similar to those in the complexes, then an approximation will be

$$
\Omega_{0}(Q)=\gamma^{* N(1-Q)}
$$

Where $\gamma^{*}$ is an experimental value for compact configurations. In the case of protein folding, we have $\gamma^{*} \simeq 1.5$ Frauenfelder et al. (1991); Frauenfelder (1997); Wolynes and Luthey-Schulten (1997) .

The entropy will decrease as the complex is approached.

$$
S_{0}(Q)=k_{B} \log \Omega_{0} \simeq k_{B} N(1-Q) \log \gamma *
$$

So that in the minimum of the rugged funnel (See figure 10 above) we would have compact, closed packed configurations, which precisely are our complexes $[S A R S-\mathrm{CoV}-2] \oplus[P M]$.

The density of conformational states with energy E and the order parameter $\mathrm{Q}$ will be

$$
\Omega(E, Q)=\Omega_{0}(Q) P(E)
$$

such that the total entropy will be

$$
S(E, Q)=S_{0}(Q)-k_{B} \frac{(E-\bar{E}(Q))^{2}}{2 \Delta E^{2}(Q)}-k_{B} \log \left(\frac{\sqrt{2 \pi \Delta E^{2}(Q)}}{\delta E}\right)
$$

where $\delta \mathrm{E}$ is large relative to the spacings between energy levels, but small relative to $\sqrt{\Delta E^{2}(Q)}$. At thermodynamic equilibrium (inside the vesicle), the most probable energy will be 


$$
E_{\text {best }}(Q)=\bar{E}(Q)-\frac{\Delta E^{2}(Q)}{k_{B} T}
$$

The entropy associated with the most probable energy will be

The free energy will be

$$
S\left(E_{\text {best }}, Q\right)=S_{0}(Q)-\frac{\Delta E^{2}(Q)}{2 k_{B} T^{2}}
$$

$$
F(Q, T)=E_{\text {best }}(Q)-T S\left(E_{\text {best }}, Q\right)=\bar{E}(Q)-\frac{\Delta E^{2}(Q)}{2 k_{B} T}-T S_{0}(Q)
$$

Definitely, free energy has relative minima either near the complex states $(Q \approx 1)$, or near the Ball states $(Q \approx 0)$. If we neglect the entropy of the complex states, its free energy will be equal to its internal energy. We thus have states of minimal entropy where the complexes $[S A R S-\mathrm{CoV}-2] \oplus[P M]$ are stabilized in compact, closed packed structures.

Finally, the local glass transition temperature will be

$$
T_{g}(Q)=\sqrt{\frac{\Delta E^{2}(Q)}{2 k_{B} S_{0}(Q)}}
$$

Recall that a transition to a "glassy state" occurs at the temperature where so few states are available such that the system remains frozen in one of few distinct states Wolynes and Luthey-Schulten (1997); Mezard et al. (2004); Fischer and Hertz (1991); Parisi (1988) (See figure 10 above).

In conclusion, we have complex [SARS-CoV-2] $\oplus[\mathrm{PM}]$, stabilized by strongly cooperative and synergistic con- formation interactions and energies.

\section{Evolution of SARS-CoV-2: mutations and quasi-species}

The evolution of the virus depends on mutations that give the parasite a selective advantage. A large viral population of SARS-CoV-2 with different genomic sequences is generally called a "quasi-species" Dimmock NJ et al. (2016).

We therefore have that the selective pressure produced by the environment in the air with polluting dusts on a quasi-species of SARS-CoV-2, not only allows the virus to survive outside the host but above all, as we have just seen, represents the fulcrum of the strategy of smart molecular attack of the parasite in its hunting environment.

In our landscape model, we can draw a lower risk margin to measure the ability of a quasi-species of SARS-CoV-2 to create a devastating impact on the host.

We can say that a quasi-species of SARS-CoV-2 have sufficient selective pressure to create a devastating impact on the host if the following conditions on entropy, energy and conformations are met, respectively:

1) $T(Q) \leq T_{g}(Q)$ (temperature of viral quasi-species)

2) the most probably energy of quasi-species is $E_{\text {best }}(Q)=\bar{E}(Q)-\frac{\Delta E^{2}(Q)}{k_{B} T}$

3) the energy variability of quasi-species is given by $\sqrt{\Delta E^{2}(Q)}$ (ruggedness)

All quasi-species that do not meet these conditions do not pose a danger to the host. In particular, the temperature condition (1) means that a dangerous quasi-species must be composed of complexes [SARS-CoV-2] $\oplus[\mathrm{PM}]$. It is clear that the most dangerous quasi-species are found in the neighborhood of $\mathrm{Q} \approx 1$ because they are the most stable and resistant. Conversely, we must not fear the quasi-species around $\mathrm{Q} \approx 0$. 
In any case, (3) defines the variability of each quasi-species such as

$$
\text { ruggedness }=\sqrt{\Delta E^{2}(Q)}
$$

where

$$
\sqrt{\Delta E^{2}(Q)} \gg \delta \mathrm{E}
$$

where $\delta \mathrm{E}$ is large with respect to the distances between the energy levels, but small with respect to the ruggedness.

\section{Landscape Prophylaxis}

For effective prophylaxis, we can avoid studying stochastic states $(\mathrm{Q} \approx 0)$, focusing only on the viral quasi-species with

1) $T(Q) \leq T_{g}(Q)$

2) $\mathrm{Q} \approx 1$

this should also lead to considerable technical and economic savings for the companies that produce the vaccines.

\section{Methodological prescriptions for addressing the study of the pandemic}

The considerations proposed in this work are intended to suggest a prescription on research methods.

In fact, we noted that in most of the studies and textbooks cited, SARS-CoV-2 is described and represented in se ipsum, i.e. regardless of the environment, as if the viral particle (also as a protein, as well as any living organism or part of a living organism) could exist without its environment, in the vacuum (nihil sine causa datum est).This is a serious systematic error.

With this position, all resulting outcomes are affected by systematic errors. As a consequence of this, any predictions based on theoretical models or experiments that do not take into account the contribution of the environment are unreliable. Furthermore, all simulations and models that consider the environment as a "fixed background" are unreliable.

It is therefore necessary (and sufficient) that each acquisition of biological samples is accompanied by a precise environmental sampling in the same intervals and conditions of space and time.

So for any model based on molecular and atomistic simulations.

\section{Conclusions}

In this work a methodological problem has been addressed concerning the research on the COVID-19 pandemic caused by the new coronavirus SARSCoV-2.

From a careful examination of the scientific literature in subiecta materia, we have noticed that the study and characterization of SARS-CoV-2 lacks a correct thermodynamic description.

That is, the viral particle is described and represented in se ipsum, i.e. independently of the environment, as if the viral particle (also as a protein, as well as any living organism or part of a living organism) could exist without its environment, in a vacuum (nihil sine causa datum est). This is a serious systematic error.

With this position, all resulting results are affected by systematic errors. Consequently, any predictions based on theoretical models or experiments that do not take into account the contribution of the environment are unreliable. 
Furthermore, all simulations and models that consider the environment as a "fixed background" are unreliable. This is a serious systematic error.

In the present work we therefore study the thermodynamics of SARS-CoV-2 in its hunting environment, from air transport to cellular entry into the host.

The first fundamental point is that in the study of the thermodynamics of the air environment of SARS-CoV-2, the presence of nanoparticles, dust, pollutants and other particles of an order of magnitude at least comparable to that of the viral particle cannot be overlooked.

This work therefore starts from a comparative study of the environments in China and Italy, the first countries affected by the infection. When the present study began (February 2020) there was still no evidence of a correlation between the spread of infection and pollution, but today there is a lot of experimental evidence of this. Indeed, many studies agree that the countries most affected by the pandemic are also the most polluted. Aside from the initial case of China and Italy, we therefore have evidence of this correlation in other countries hard hit by the pandemic such as the United States, Mexico, the United Kingdom, Brazil and others.

We therefore propose a theory of the energy landscape of the cooperative and synergistic complexes that the new SARS-CoV-2 coronavirus forms with particulate dust and other pollutants.

This model explains both the effects of the selective pressure exerted by the environment on the parasite, and the emergence of devastating viral quasi-species, tracing in a single formalism the main variables and parameters that describe the complexification phenomenon of the virus in the environment.

It explains in particular why the complexification of the parasite due to the environmental selective pressure in the environment is not only necessary for its survival and reproductive strategy, but at the same time has a devastating effect for the host species.

Ultimately, based on this model it is therefore possible:

1) on the one hand, explain the thermodynamics of the phenomenon to avoid the onset of dangerous systematic errors

2) on the other hand, to devise new research tools and methods to study the evolution and spread of the infection (landscape model)

3 ) at the same time, improve vaccination prophylaxis, focusing research on the most dangerous quasi-viral species $(\mathrm{Q} \approx 1)$, saving time, resources and costs for the companies that produce the vaccines.

\section{Ways to proceed in the future}

After a correct sampling of the organic materials and the environmental background, in the same space-time intervals and in the same physical conditions, the thermodynamics of the system can be correctly defined according to the observations outlined here. Therefore, viral quasi-species can be analyzed as a function of energies and configurations, from which it is possible to trace an experimental landscape for each micro-area of study, which will guide us in the analysis and simulations, as explained in this work.

The first thing to do is to create a diagram of the viral quasi-species identified so far as a function of the average (free) energies measured in the same environmental conditions as the background. Each micro-region must have its own diagram. For example, we will have the Lombardy diagram for a certain time interval, the Wuhan diagram and so on. For each quasi-species we will have 
to identify the danger on the basis of the tables generated and updated from time to time by the health institutes and scientific committees of each country. The intersection of the diagram with the most dangerous species will provide us with some points in the neighborhood of the control parameter $\mathrm{Q} \approx 1$. These will be our experimental minima of the free energy, which will help us to build our experimental landscape, which will serve as a condition for outline to proceed with the simulations and models of the evolution of the disease. From which it is easy to calculate the various coefficients such as contagion indices and so on.

We reserve further information and updates.

\section{Acknowledgments}

The author acknowledges the:

- Ministry of Environment and Ecology of the People's Republic of China;

- The European Commission;

- The European Environment Agency;

○ The U.S. Environmental Protection Agency;

- World Health Organization;

Italian Government;

- Istituto Superiore di Sanità (Italian National Institute of Health);

- Prof. Giorgio Parisi, President of the Accademia Nazionale dei Lincei;

- Regione Lombardia, Italy;

- The People's Government of Wuhan, China;

- The World Wildlife Fund - WWF;

- National Scientific Council of Italy - CNR;

- Coronavirus Disease Research Community - COVD-19 at CERN, Genève, Switzerland.

\section{References}

European Environment Agency -EEA (2019) Health impacts of air pollution. URL https://www.eea.europa.eu/publications/air-quality-in-europe-2019

European Environment Agency -EEA (2019-2020) Italy - Air pollution country fact sheet 2019. https://www.eea.europa.eu/themes/air/countryfact-sheets/2020-country-fact-sheets/italy

Anenberg SC, Achakulwisut P, Brauer M, Moran D, Apte JS, Henze DK (2019) Particulate matter-attributable mortality and relationships with carbon dioxide in 250 urban areas worldwide. Scientific Reports 9(1):11552-11552, DOI 10.1038/s41598-019-48057-9, URL https://dx.doi.org/10.1038/s41598-019-48057-9 
Accademia Nazionale dei Lincei (2021) - COVID-19 Commission directed by G Parisi https://www.lincei.it/it/covid-19-documenti-dellaccademia-dei-lincei

Cascella M, Rajnik M, Cuomo A, et al. (2020) Evaluation and Treatment Coronavirus (COVID-19) - Updated 2020 Apr 6, statpearls publishing edn. Treasure Island (FL), USA, URL https://www.ncbi.nlm.nih.gov/books/NBK554776/

Corriere della Sera (2020-2021) COVID-19 pandemics in Italy The contagion map updated is available at the following URL https://www.corriere.it/salute/mappa-coronavirus-italia-dati-contagiocovid19/index.shtml

CHINA National Environmental Monitoring Centre - CNEMC (2020) PM2.5 concentrations at 1280 stationary sites. URL http://www.cnemc.cn/en/

CERN, Geneve, CH (2020a) CERN against COVID-19. URL

https://againstcovid19.cern/

CERN, Geneve, CH (2020b) folding@home. URL

https://againstcovid19.cern/actions/cern-contributes-computerscombattingcovid-19

CERN, Geneve, CH (2020c) ZENODO - COVID-19 related communities. URL https://zenodo.org/

Dan Liang et al. (2019) National air pollution distribution in China and related geographic, gaseous pollutant, and socio-economic factors. Environ Pollut (250):998-1009, DOI 10.1016/j.envpol.2019.03.075, URL

https://www.ncbi.nlm.nih.gov/pubmed/31085487

Dimmock NJ, et al. (2016) Introduction to Modern Virology. In: Introduction to Modern Virology - Seventh Edition, John Wiley \& Sons, Ltd, 9600, Garsington Road, Oxford, OX4 2DQ, UK

Ministry of Ecology of the People's Republic of China (2017) Report on the State of the Ecology and Environment in China 2017. http://english.mee.gov.cn/Resources/Reports/soe/SOEE2017/201808/P02 0180801597738742758.pdf

Scientific Committee on Emerging and Newly Identified Health Risks (SCENIHR) at the European Commission (2006) The appropriateness of existing methodologies to assess the potential risks associated with engineered and adventitious products of nanotechnologies. URL https://ec.europa.eu/health/ph risk/documents/synth report.pdf

United States Environmental Protection Agency - EPA (2020) Particulate Matter (PM) Pollution. URL

https://www.epa.gov/pm-pollution/health-and-environmental-effectsparticulate-matter-pm

Fischer KH, Hertz JA (1991) Spin Glasses. Cambridge Studies in Magnetism, Cambridge University Press

Frauenfelder H (1997) The Complexity of Proteins. In: Physics of Biological Systems, Springer

Frauenfelder H (2005) Energy Landscape and Dynamics of Biomolecules Extended Abstract. Journal of Biological Physics 31(3-4):413-416, DOI 10.1007/s10867-005-0696-4, URL

https://dx.doi.org/10.1007/s10867-005-0696-4

Frauenfelder H, Sligar S, Wolynes P (1991) The energy landscapes and motions of proteins. Science 254(5038):1598-1603, DOI 10.1126/science.1749933, URL https://dx.doi.org/10.1126/science.1749933

Friedlander SK, NSF, Southern California Particle Center, and UCLA Department of Chemical Engineering, et al. (2003) Emerging Issues in Nanoparticle Aerosol Science and Technology (NAST). URL

http://www.eng.uc.edu/ beaucag/Classes/MorphologyofComplexMaterials/NSFAer osolPar\%20Report.pdf

Trewyn B, et al. (2008) Biocompatible mesoporous silica nanoparticles with different morphologies for animal cell membrane penetration. Chemical Engineering Journal 137(1):23-29, DOI https://doi.org/10.1016/ j.cej.2007.09.045, URL

https://doi.org/10.1016/j.cej.2007.09.045 
Hongliang Wang et al. (2008) SARS coronavirus entry into host cells through a novel clathrin- and caveolae-independent endocytic pathway. Cell Res 18(2):290-301, DOI https://doi.org/10.1038/cr.2008.15, URL https://doi.org/10.1038/cr.2008.15

Scientific Committee on Health and Environmental Risks -SCHER (2005) New evidence of air pollution effects on human health and the environment

https://ec.europa.eu/health/archive/ph_risk/committees/04_scher/docs/scher_o_009. pdf

Italian Society of Enviromental Medicine (2020) Position paper and "Relazione circa l'effetto dell'inquinamento da particolato atmosferico e la diffusione di virus nella popolazione" https://www.simaonlus.it/?page id=694

Kuerban M, et al. (2020) Spatio-temporal patterns of air pollution in China from 2015 to 2018 and implications for health risks. Environmental Pollution 258, DOI https://doi.org/10.1016/j.envpol.2019.113659

Liu D, Lin T, Syed JH (2017) Concentration, source identification, and exposure risk assessment of PM2.5-bound parent PAHs and nitro-PAHs in atmosphere from typical Chinese cities. Sci Rep 7:10398-10398

Liu Y et al. (2020) Aerodynamic Characteristics and RNA Concentra- tion of SARS-CoV-2 Aerosol in Wuhan Hospitals during COVID-19 Outbreak. bioRxiv preprint DOI https://doi.org/10.1101/2020.03.08.982637, URL https://doi.org/10.1101/2020.03.08.982637

Lombardia R, Regione Lombardia (2020) Lombardy territory and population. URL

https://www.regione.lombardia.it/wps/portal/istituzionale/\%20HP/Dettagl ioRedazionale/scopri-la-lombardia/Territorio-epopolazione $/ \% 20$ Territorio $+\mathrm{e}+$ popolazione/red-territorio-e-popolazione$\underline{\mathrm{REC}}$

MacNee W et al. (2003) Mechanism of lung injury caused by PM10 and ultrafine particles with special reference to COPD. European Respiratory Journal (40):47s-51s, DOI 10.1183/09031936.03.00403203, URL

https://erj.ersjournals.com/content/21/40 suppl/47s

Mezard M, Parisi G, Virasoro M (2004) Spin Glass Theory and Beyond. World Scientific

Mike Z He, et al. (2017) Fine Particulate Matter Concentrations in Urban Chinese Cities, 2005-2016: A Systematic Review. Int J Environ Res Public Health DOI 10.3390/ijerph14020191, URL

https://pubmed.ncbi.nlm.nih.gov/28216601/

Oberfield B, et al. (2020) COVID-19 snapshot. Cell URL

https://www.cell.com/pb-assets/products/coronavirus/CELL_11362_S5.pdf

Parisi G (1988) Statistical Field Theory. Frontiers in Physics, Addison-Wesley Publishing Company

Pasini A, CNR- Consiglio Nazionale delle Ricerche (2020) Climate Change and COVID-19 in an equation. URL

http://www.cnrweb.tv/cambiamenti-climatici-e-covid-19-in-unequazione/

Pratesi I, Galaverni M, WWF Italia, et al. (2020) Pandemie, l'effetto boomerang della distruzione degli ecosistemi. URL

https://www.wwf.it/pandemie_e distruzione_degli_ecosistemi/ 
Rongshan Wu et al. (2018) Are current Chinese national ambient air quality standards on 24-hour averages for particulate matter sufficient to protect public health? J Environ Sci (China) (71):67-75, DOI

https://doi.org/10.1016/j.jes.2018.01.017

Ren M, et al. (2017) The short-term effects of air pollutants on respiratory disease mortality in Wuhan, China: comparison of time-series and case- crossover analyses. Scientific Reports 7(40482), DOI 10.1038/srep40482, URL 10.1038/srep40482

Rohde RA, Muller RA (2015) Air Pollution in China: Mapping of Concentrations and Sources. PLOS ONE 10(8):e0135749-e135749, DOI 10. 1371/journal.pone.0135749, https://dx.doi.org/10.1371/journal.pone.0135749

Setti, Leonardo, et al. (2020) Potential role of particulate matter in the spreading of COVID-19 in Northern Italy: first observational study based on initial epidemic diffusion. BMJ open, 2020, 10.9: e039338.

Walls AC, et al. (2020) Structure, Function, and Antigenicity of the SARSCoV-2 Spike Glycoprotein. Cell 181(2):281-292.e6, DOI https://doi.org/10. 1016/j.cell.2020.02.058, URL https://doi.org/10.1016/j.cell.2020.02.058

Wang W, Zhao S, Jiao L (2019) Estimation of PM2.5 Concentrations in China Using a Spatial Back Propagation Neural Network. Sci Rep 9:13788-13788

Wolynes PG, Luthey-Schulten Z (1997) The Energy Landscape Theory of Protein Folding. In: Physics of Biological Systems, Springer

Wu MX, et al. (2020) Exposure to air pollution and COVID-19 mortality in the United States: A nationwide cross-sectional study. MedRxiv preprint URL https://www.medrxiv.org/content/10.1101/2020.04.05.20054502v1

Wu, X., Nethery, R. C., Sabath, M. B., Braun, D. and Dominici, F., 2020. Air pollution and COVID-19 mortality in the United States: Strengths and limitations of an ecological regression analysis. Science advances, 6(45), p.eabd4049.

The Government of Wuhan (2020) Wuhan Population and Territory. URL

http://english.wh.gov.cn/whgk_3581/dqrk/201809/t20180913_227369.html

Xing YF, et al. (2016) The impact of PM2.5 on the human respiratory system. J Thorac Dis 8(1):E69-E74, DOI https://dx.doi.org/10.3978/j.issn.20721439.2016.01.19, URL

https://dx.doi.org/10.3978/j.issn.2072-1439.2016.01.19

$\mathrm{Xu}$ D, et al. (2020) Acute effects of ambient PM2.5 on lung function among schoolchildren. Scientific Reports 10(4061), DOI https://doi.org/10.1038/ s41598-020-61003-4, URL https://doi.org/10.1038/s41598-020-61003-4

Yanhong Zhu et al. (2018) Sources of particulate matter in China: Insights from source apportionment studies published in 1987-2017. Environ Int (115):343357, DOI 10.1016/j.envint.2018.03.037

https://doi.org/10.1016/j.envint.2018.03.037

Yan R, et al. (2020) Structural basis for the recognition of the SARS-CoV2 by full-length human ACE2. Science DOI 10.1126/science.abb2762, URL https://science.sciencemag.org/content/early/2020/03/03/science.abb2762

Zhang L, et al. (2020) Crystal structure of SARS-CoV-2 main protease provides a basis for design of improved $\alpha$-ketoamide inhibitors.

Science DOI 10. 1126/science.abb3405, URL

https://science.sciencemag.org/content/early/2020/03/19/science.abb3405 
Zhang Y, Cao F (2015) Fine particulate matter (PM2.5) in China at a city level. Sci Rep 5:14884-14884

Zhao B, et al. (2018) Change in household fuels dominates the decrease in PM2.5 exposure and premature mortality in China in 2005-2015. PNAS 115(49):12401-12406, DOI https://doi.org/10.1073/pnas.1812955115, URL https://www.pnas.org/content/115/49/12401 


\section{List of Figures}

1 Percentage of 338 Chinese Cities with Different Concentrations of Six Major Pollutants in 2017 (courtesy of the Chinese Ministry of the Environment and Ecology of Ecology and of the People's Republic of China (2017) ). Note the high percentage values of PM 10 and PM 2.5 .................................................. 15

2 Air Quality Comprehensive Index and Primary Pollutants of 74 Cities in 2017 (courtesy of the Chinese Ministry of the Environment and Ecology of Ecology and of the People's Republic of China (2017) ). Note the preponderance of PM2.5 $_{2}$ among the primary pollutants, also for the city of Wuhan.

3 Italy - Air pollution country fact sheet 2019 (courtesy of European Environemnt Agency (2019b) ) .

4 The PM2.5 annual mean concentrations in 2017 in Italy compared to the EU annual limit value $(25 \mu \mathrm{g} / \mathrm{m} 3)$ (Left) The PM10 percentile 90.41 concentrations in 2017 in Italy compared to the EU daily limit value $(50 \mu \mathrm{g} / \mathrm{m} 3)$ (Right).

Note that the highest values of Particulate Matter are reached in the regions of Northern Italy, particularly for PM 2.5. Courtesy of the European Environment Agency (2019b)

5 Contagion maps in Italy. Top left - situation on 25 April 2020. Top right - situation on 12 June 2020 - Center- situation update March $11^{\text {th }} 2021$ (courtesy of Corriere della Sera della Sera (2020)). If we compare these maps with the previous figures 4 , we immediately notice that the areas most affected by the pandemic are the most polluted. Here we find the same type of correlation studied by T.H. Chan School of Public Health at Harvard Wu et al. (2020)

6 Entry of animal virus genomes into cells (courtesy of NJ Dimmock et Al. Dimmock et al. (2016) ).

7 Snapshot of a simulation of a SARS-CoV-2 ball with its environment for a low density of UFP dust from $0.025 \mu \mathrm{m}$ to $0.100 \mu \mathrm{m}$.

8 Snapshot of a simulation of the endocytosis of SARS-CoV-2 with its environment (ball) low UFP dust $0.025 \mu \mathrm{m}-0.100 \mu \mathrm{m} 22$

9 SARS-CoV-2 with its environment inside a vesicle, as an isolated thermodynamic system. Universe (SARS-CoV-2 with its environment) and the rest of the universe (environment). low UFP dust $0.025 \mu \mathrm{m}-0.100 \mu \mathrm{m}$

10 Energy rugged funnel landscape for $[\mathrm{SARS}-\mathrm{CoV}-2] \oplus[\mathrm{PMs}]$ complex formation. 

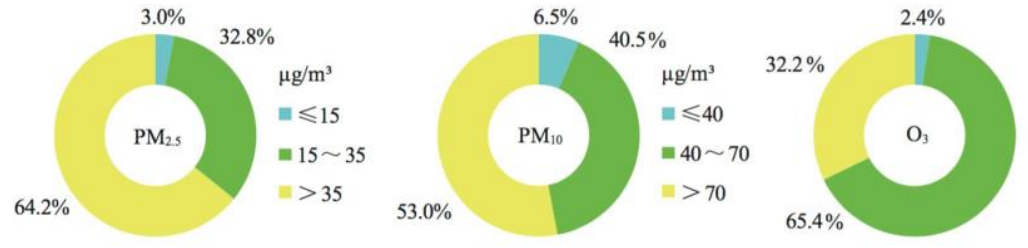

$\mu \mathrm{g} / \mathrm{m}^{3}$

$=100$

- $100 \sim 160$

포 $>160$
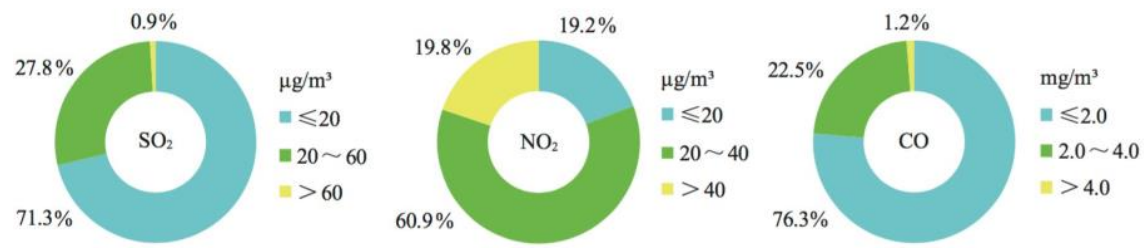

Fig. 1 Percentage of 338 Chinese Cities with Different Concentrations of Six Major Pollutants in 2017 (courtesy of the Chinese Ministry of the Environment and Ecology of Ecology and of the People's Republic of China (2017) ). Note the high percentage values of PM 10 and PM 2.5 


\begin{tabular}{|c|c|c|c|c|c|c|c|c|c|}
\hline No. & City & $\begin{array}{c}\text { Compre- } \\
\text { hensive } \\
\text { index }\end{array}$ & $\begin{array}{c}\text { Maximum } \\
\text { index }\end{array}$ & $\begin{array}{l}\text { Primary } \\
\text { pollutant }\end{array}$ & No. & City & $\begin{array}{c}\text { Compre- } \\
\text { hensive } \\
\text { index }\end{array}$ & $\underset{\text { index }}{\text { Maximum }}$ & $\begin{array}{l}\text { Primary } \\
\text { pollutant }\end{array}$ \\
\hline 1 & Haikou & 2. 49 & 0.79 & $\mathrm{O}_{3}$ & 38 & Hangzhou & 5.02 & 1.29 & $\mathrm{PM}_{2.5}$ \\
\hline 2 & Lhasa & 3.13 & 0.80 & $0_{3}$ & 39 & Chongqing & 5.04 & 1.29 & $\mathrm{PM}_{2.5}$ \\
\hline 3 & Zhoushan & 3. 18 & 0.95 & $0_{3}$ & 40 & Xining & 5.11 & 1. 19 & $\mathrm{PM}_{10}$ \\
\hline 4 & Xiamen & 3. 37 & 0.80 & $\mathrm{NO}_{2}$ & 41 & Nanjing & 5.18 & 1.18 & $\mathrm{NO}_{2}$ \\
\hline 5 & Fuzhou & 3.42 & 0.88 & $\mathrm{O}_{3}$ & 42 & Huai'an & 5.18 & 1.43 & $\mathrm{PM}_{2.5}$ \\
\hline 6 & Huizhou & 3. 48 & 0.89 & $\mathrm{O}_{3}$ & 43 & Taizhou & 5.22 & 1.46 & $\mathrm{PM}_{2,5}$ \\
\hline 7 & Shenzhen & 3. 49 & 0.92 & $\mathrm{O}_{3}$ & 44 & Changchun & 5.22 & 1. 31 & $\mathrm{PM}_{2,5}$ \\
\hline 8 & Lishui & 3.54 & 0.94 & $\mathrm{PM}_{2.5}$ & 45 & Wuxi & 5.28 & 1.26 & $\mathrm{PM}_{2.5}$ \\
\hline 9 & Guiyang & 3.61 & 0.91 & $\mathrm{PM}_{2.5}$ & 46 & Suqian & 5.34 & 1.57 & $\mathrm{PM}_{2.5}$ \\
\hline 10 & Zhuhai & 3.64 & 1.00 & $0_{3}$ & 47 & Changzhou & 5.41 & 1. 37 & $\mathrm{PM}_{2,5}$ \\
\hline 11 & Taizhou & 3.65 & 0.94 & $\mathrm{PM}_{2.5}$ & 48 & Wuhan & 5.46 & 1.49 & $\mathrm{PM}_{2.5}$ \\
\hline 12 & Kunming & 3. 76 & 0.83 & $\mathrm{PM}_{10}$ & 49 & Zhenjiang & 5.63 & 1. 57 & $\mathrm{PM}_{2.5}$ \\
\hline 13 & Nanning & 3.95 & 1.00 & $\mathrm{PM}_{2.5}$ & 50 & Hefei & 5.65 & 1.60 & $\mathrm{PM}_{2.5}$ \\
\hline 14 & Dalian & 4. 15 & 1. 02 & $0_{3}$ & 51 & Harbin & 5.71 & 1.66 & $\mathrm{PM}_{2.5}$ \\
\hline 15 & Zhongshan & 4. 16 & 1.13 & $0_{3}$ & 52 & Yangzhou & 5.72 & 1.54 & $\mathrm{PM}_{2.5}$ \\
\hline 16 & Zhang jiakou & 4. 18 & 1.08 & $\mathrm{O}_{3}$ & 53 & Shenyang & 5.78 & 1.43 & $\mathrm{PM}_{2.5}$ \\
\hline 17 & Ningbo & 4. 31 & 1.06 & $\mathrm{PM}_{2.5}$ & 54 & Chengdu & 5.85 & 1.60 & $\mathrm{PM}_{2.5}$ \\
\hline 18 & Quzhou & 4. 37 & 1.20 & $\mathrm{PM}_{2.5}$ & 55 & Qinhuangdao & 5.86 & 1.26 & $\mathrm{PM}_{2.5}$ \\
\hline 19 & Dongguan & 4. 37 & 1.06 & $\mathrm{O}_{3}, \mathrm{PM}_{2.5}$ & 56 & Beijing & 5.87 & 1.66 & $\mathrm{PM}_{2.5}$ \\
\hline 20 & Wenzhou & 4.40 & 1.09 & $\mathrm{PM}_{2.5}$ & 57 & Hohhot & 5.93 & 1. 36 & $\mathrm{PM}_{10}$ \\
\hline 21 & Jinhua & 4. 44 & 1.20 & $\mathrm{PM}_{2.5}$ & 58 & Yinchuan & 6.41 & 1.51 & $\mathrm{PM}_{10}$ \\
\hline 22 & Zhaoqing & 4. 47 & 1. 17 & $\mathrm{PM}_{2.5}$ & 59 & Lanzhou & 6.45 & 1.59 & $\mathrm{PM}_{10}$ \\
\hline 23 & Yancheng & 4.58 & 1.23 & $\mathrm{PM}_{2.5}$ & 60 & Tianjin & 6.53 & 1. 77 & $\mathrm{PM}_{2.5}$ \\
\hline 24 & Jiangmen & 4.60 & 1. 21 & $0_{3}$ & 61 & Urumchi & 6.55 & 2.00 & $\mathrm{PM}_{2,5}$ \\
\hline 25 & Guangzhou & 4. 61 & 1. 30 & $\mathrm{NO}_{2}$ & 62 & Langfang & 6.61 & 1. 71 & $\mathrm{PM}_{2.5}$ \\
\hline 26 & Shanghai & 4.63 & 1. 13 & $\mathrm{O}_{3}$ & 63 & Xuzhou & 6.78 & 1.94 & $\mathrm{PM}_{2.5}$ \\
\hline 27 & Jiaxing & 4. 72 & 1.20 & $\mathrm{PM}_{2,5}$ & 64 & Cangzhou & 6.89 & 1.89 & $\mathrm{PM}_{2,5}$ \\
\hline 28 & Shaoxing & 4. 73 & 1.29 & $\mathrm{PM}_{2.5}$ & 65 & Jinan & 7.04 & 1.86 & $\mathrm{PM}_{2,5}$ \\
\hline 29 & Foshan & 4. 75 & 1. 14 & $\mathrm{PM}_{2.5}$ & 66 & Zhengzhou & 7.07 & 1.89 & $\mathrm{PM}_{2.5}$ \\
\hline 30 & Nanchang & 4. 75 & 1. 17 & $\mathrm{PM}_{2.5}$ & 67 & Hengshui & 7.29 & 2. 20 & $\mathrm{PM}_{2,5}$ \\
\hline 31 & Qingdao & 4. 78 & 1. 11 & $\mathrm{PM}_{10}, \mathrm{PM}_{2.5}$ & 68 & Xi'an & 7. 72 & 2. 17 & $\mathrm{PM}_{2.5}$ \\
\hline 32 & Lianyungang & 4. 79 & 1.29 & $\mathrm{PM}_{2.5}$ & 69 & TaiYuan & 7. 79 & 1.89 & $\mathrm{PM}_{2,5}$ \\
\hline 32 & Nantong & 4. 79 & 1. 12 & $\mathrm{O}_{3}$ & 70 & Tangshan & 7. 97 & 1.89 & $\mathrm{PM}_{2,5}$ \\
\hline 34 & Huzhou & 4.80 & 1. 20 & $\mathrm{PM}_{2.5}$ & 71 & Baoding & 8.32 & 2. 40 & $\mathrm{PM}_{2.5}$ \\
\hline 35 & Chengde & 4. 86 & 1. 17 & $\mathrm{PM}_{10}$ & 72 & Xingtai & 8.57 & 2. 29 & $\mathrm{PM}_{2.5}$ \\
\hline 36 & Suzhou & 4. 97 & 1. 20 & $\mathrm{NO}_{2}, \mathrm{PM}_{2.5}$ & 73 & Handan & 8.64 & 2. 46 & $\mathrm{PM}_{2.5}$ \\
\hline 37 & Changsha & 4. 98 & 1. 49 & $\mathrm{PM}_{2.5}$ & 74 & Shijiazhuang & 8.72 & 2. 46 & $\mathrm{PM}_{2.5}$ \\
\hline
\end{tabular}

Fig. 2 Air Quality Comprehensive Index and Primary Pollutants of 74 Cities in 2017 (courtesy of the Chinese Ministry of the Environment and Ecology of Ecology and of the People's Republic of China (2017) ). Note the preponderance of $\mathrm{PM}_{2.5}$ among the primary pollutants, also for the city of Wuhan. 


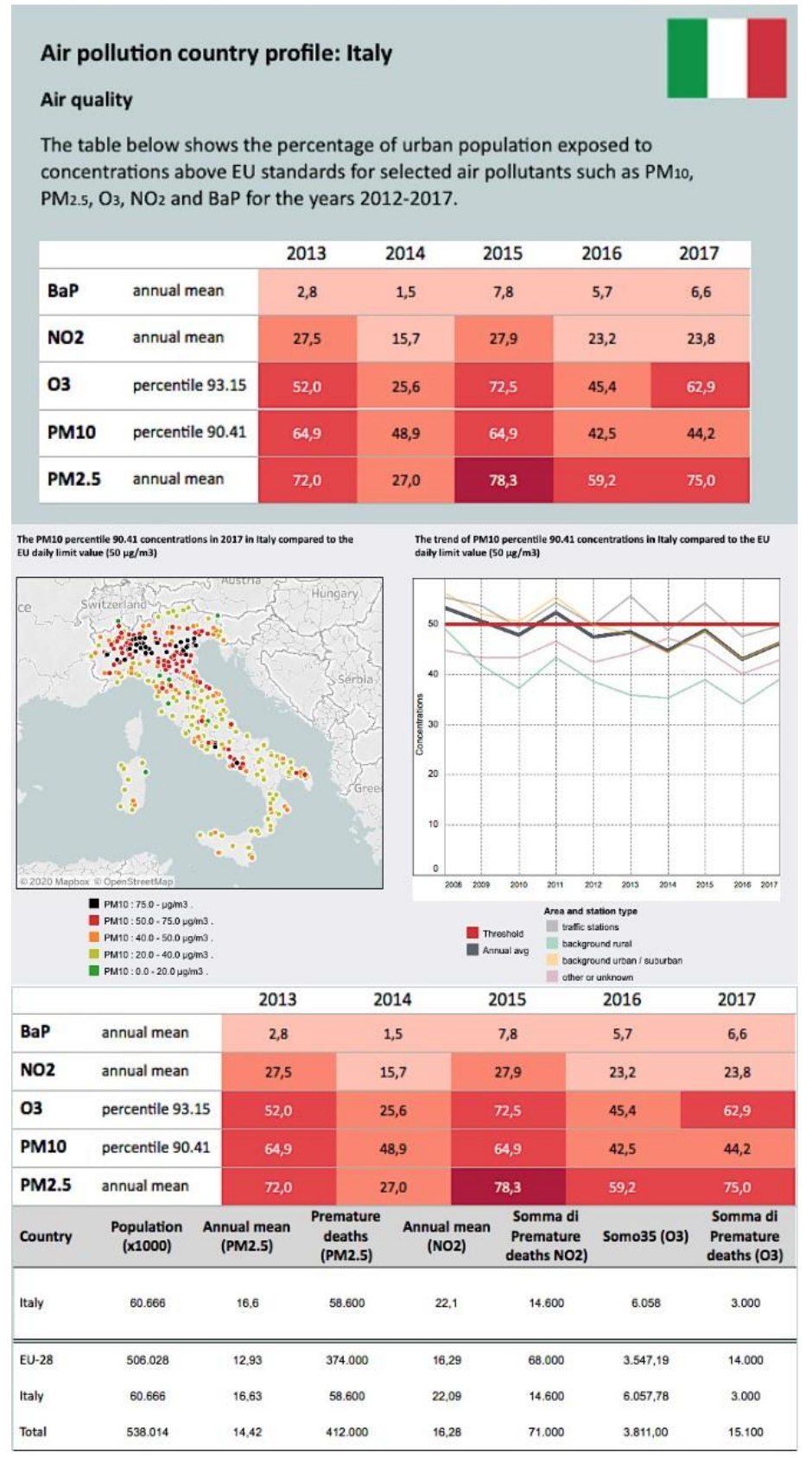

Fig. 3 Italy - Air pollution country fact sheet 2019 (courtesy of European Environemnt Agency Agency (2019b) ) 


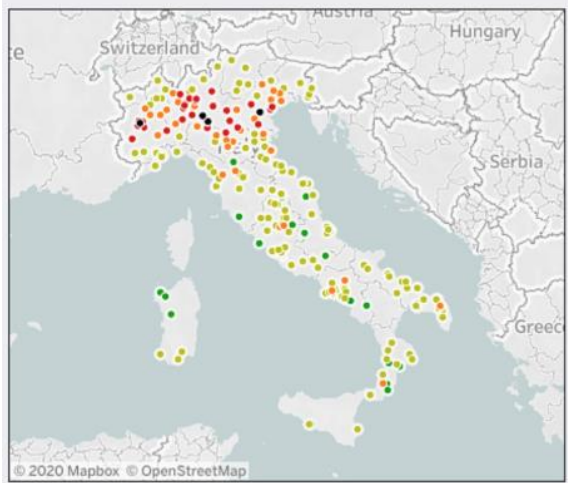
EU daily limit value $(50 \mathrm{\mu g} / \mathrm{m3})$

Fig. 4 The PM2.5 annual mean concentrations in 2017 in Italy compared to the EU annual limit value $(25 \mu \mathrm{g} / \mathrm{m} 3)$ (Left) The PM10 percentile 90.41 concentrations in 2017 in Italy compared to the EU daily limit value $(50 \mu \mathrm{g} / \mathrm{m} 3)$ (Right).

Note that the highest values of Particulate Matter are reached in the regions of Northern Italy, particularly for PM 2.5. Courtesy of the European Environment Agency Agency (2019b) 


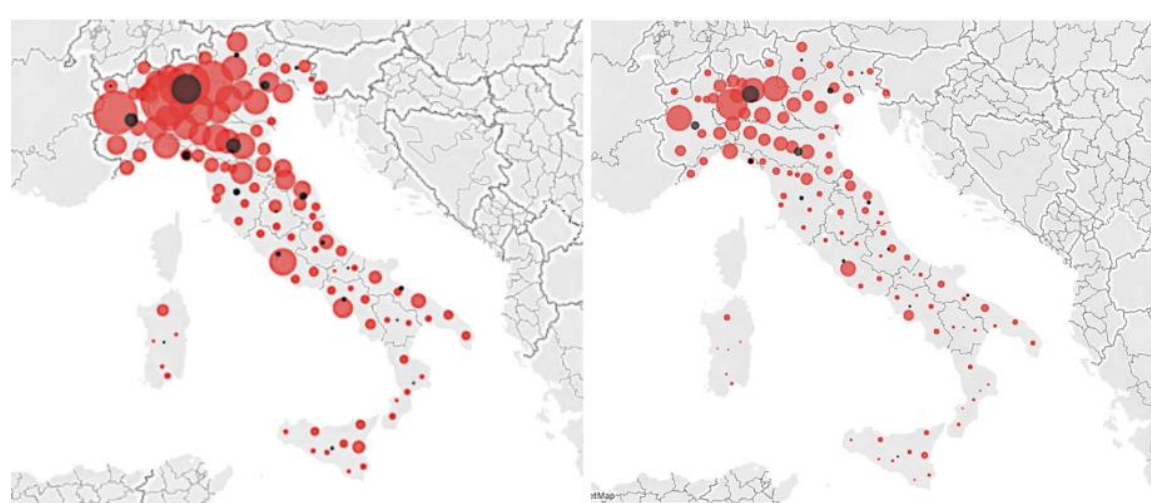

LA DIFFUSIONE GEOGRAFICA DEL VIRUS

I contagi in Italia per regione I contagi in Italia per provincia

\section{I contagi in Italia per regione}

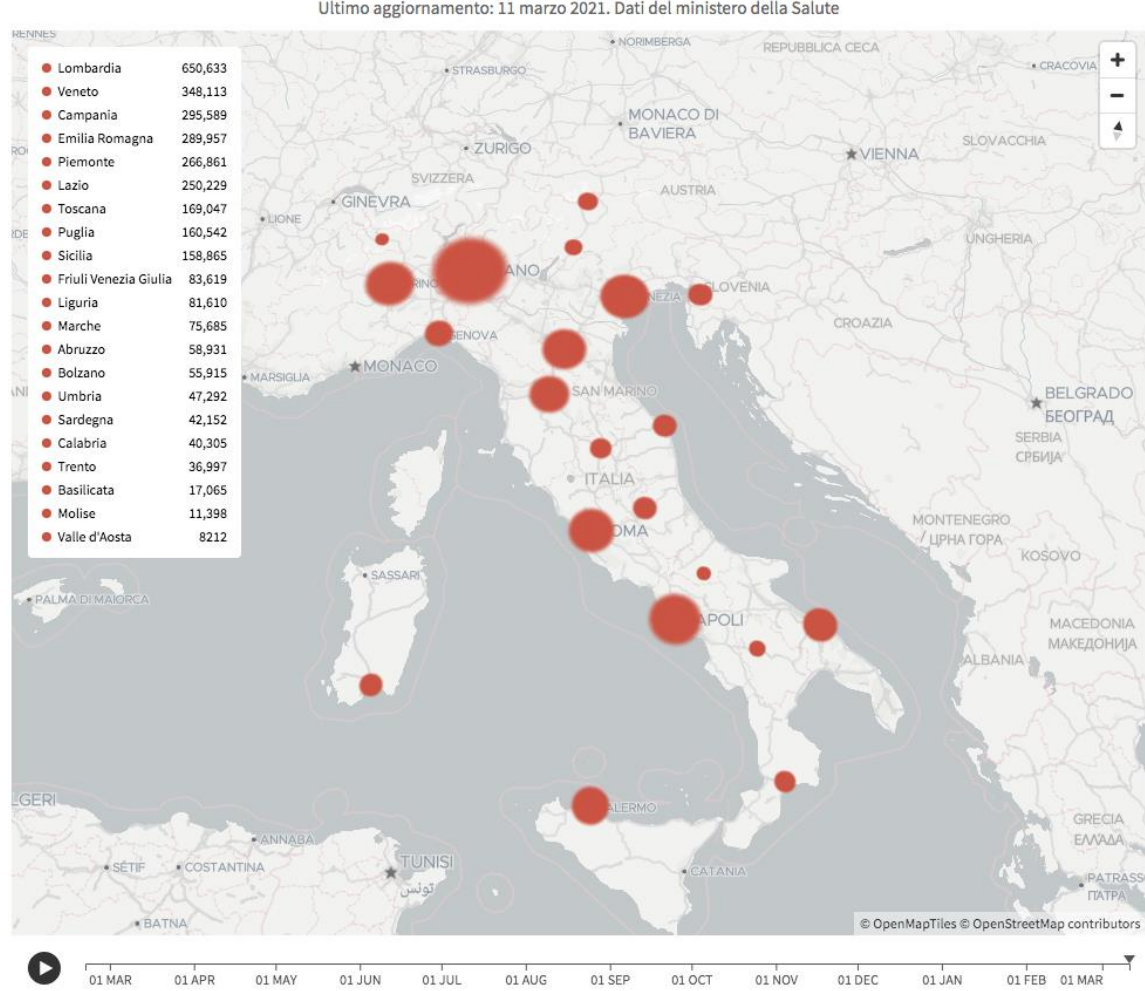

Fig. 5 Contagion maps in Italy. Top left - situation on 25 April 2020. Top right - situation on 12 June 2020 - center situation update March $11^{\text {th }} 2021$ (courtesy of Corriere della Sera della Sera (2021) ). If we compare these maps with the previous figures 4 , we immediately notice that the areas most affected by the pandemic are the most polluted. Here we find the same type of correlation studied by T.H. Chan School of Public Health at Harvard Wu et al. (2020) 
(a)

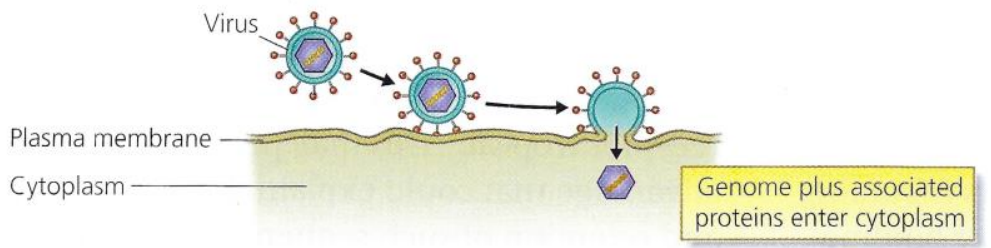

(b)

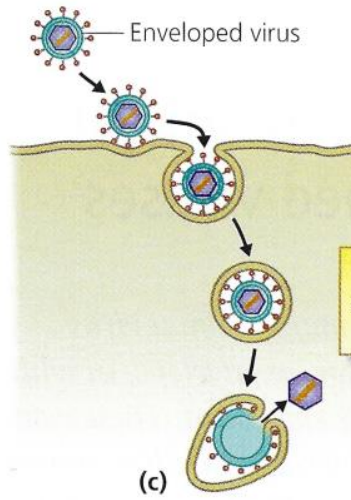

\section{Fusion with an endosome,} an intracellular vesicle which

Enveloped virus fuses with vesicle
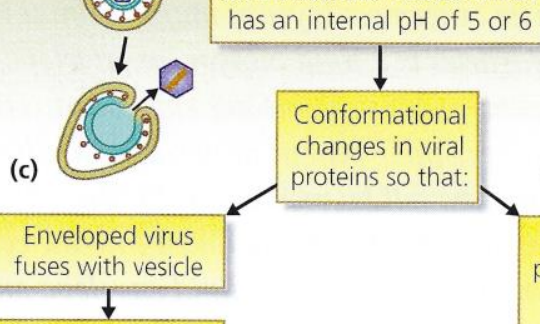

Genome plus associated proteins enter cytoplasm Conformational changes in viral proteins so that: (d)

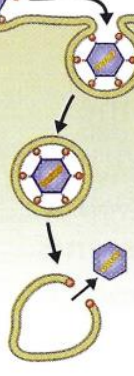

Genome plus associated proteins of non-enveloped virus escapes from the vesicle through a pore formed from viral proteins and enters cytoplasm

(e)

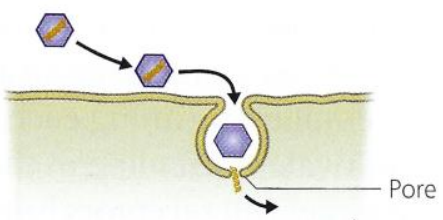

Fig. 6 Entry of animal virus genomes into cells (courtesy of NJ Dimmock et Al. Dimmock et al. (2016) ) 


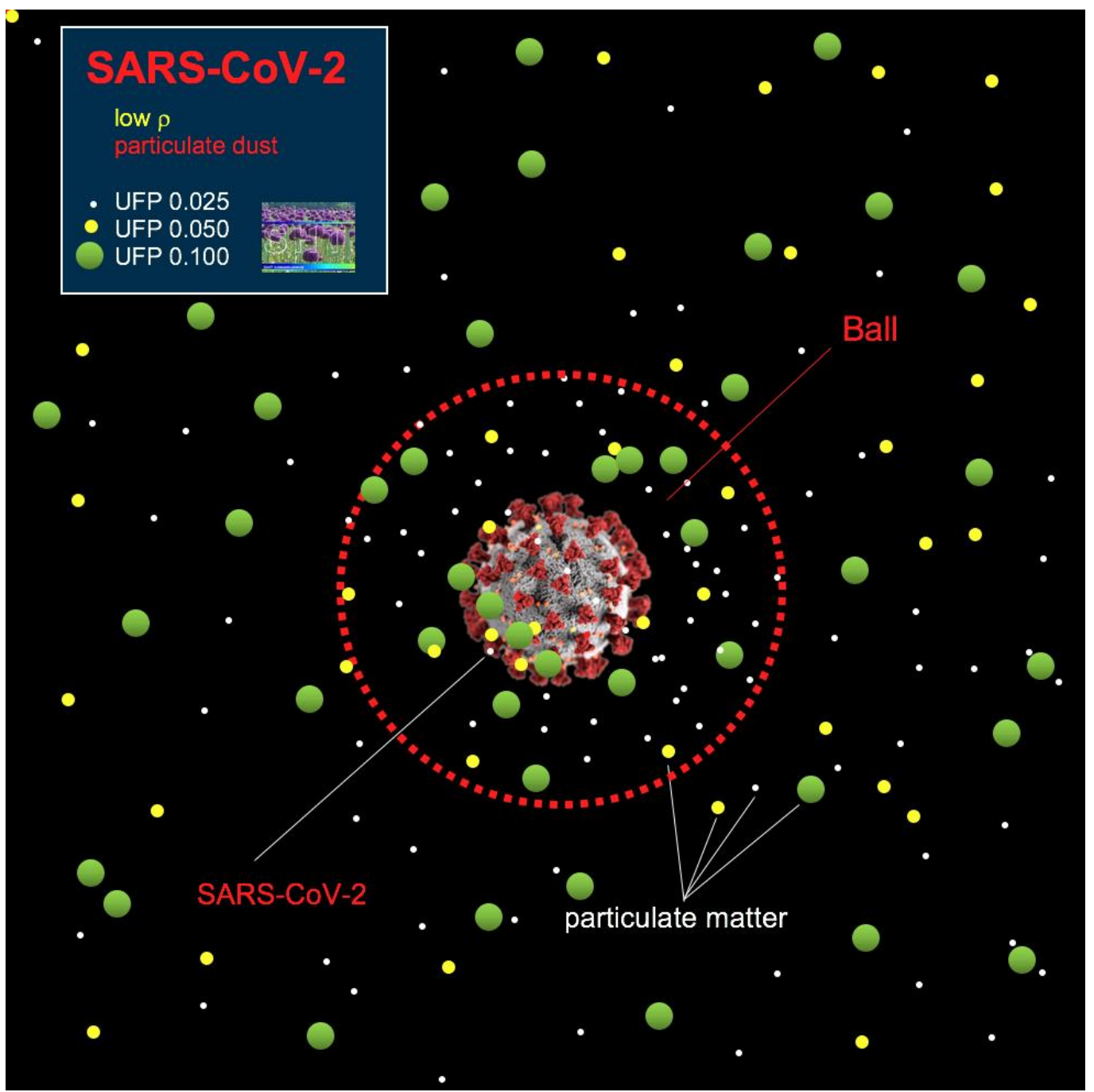

Fig. 7 Snapshot of a simulation of a SARS-CoV-2 ball with its environment for a low density UFP particulate dust from $0.025 \mu \mathrm{m}$ to $0.100 \mu \mathrm{m}$. 


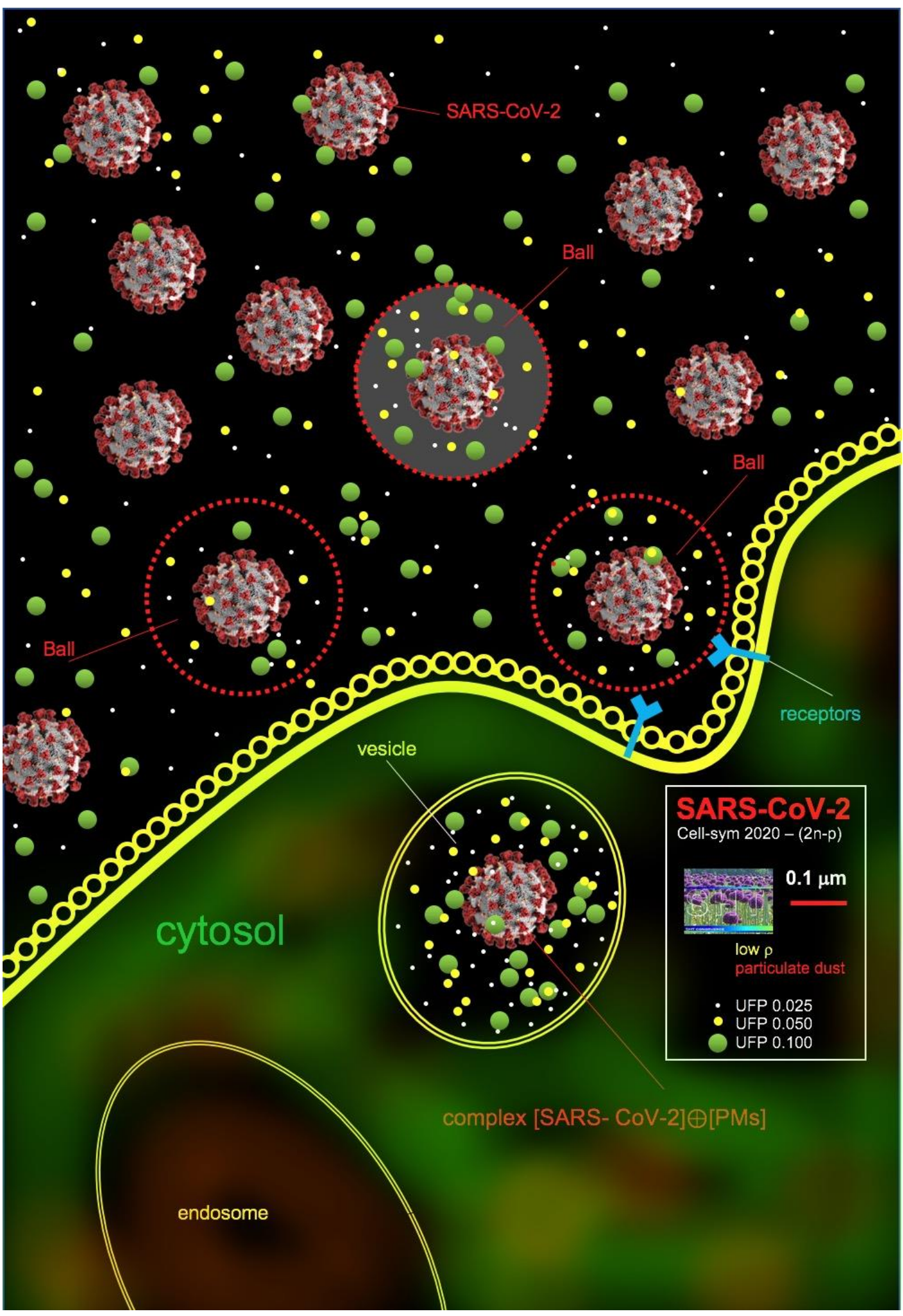

Fig. 8 Snapshot of a simulation of the endocytosis of SARS-CoV-2 with its environment (ball) low density - UFP particulate dust $0.025 \mu \mathrm{m}, 0.050 \mu \mathrm{m}$ and $-0.100 \mu \mathrm{m}$ 


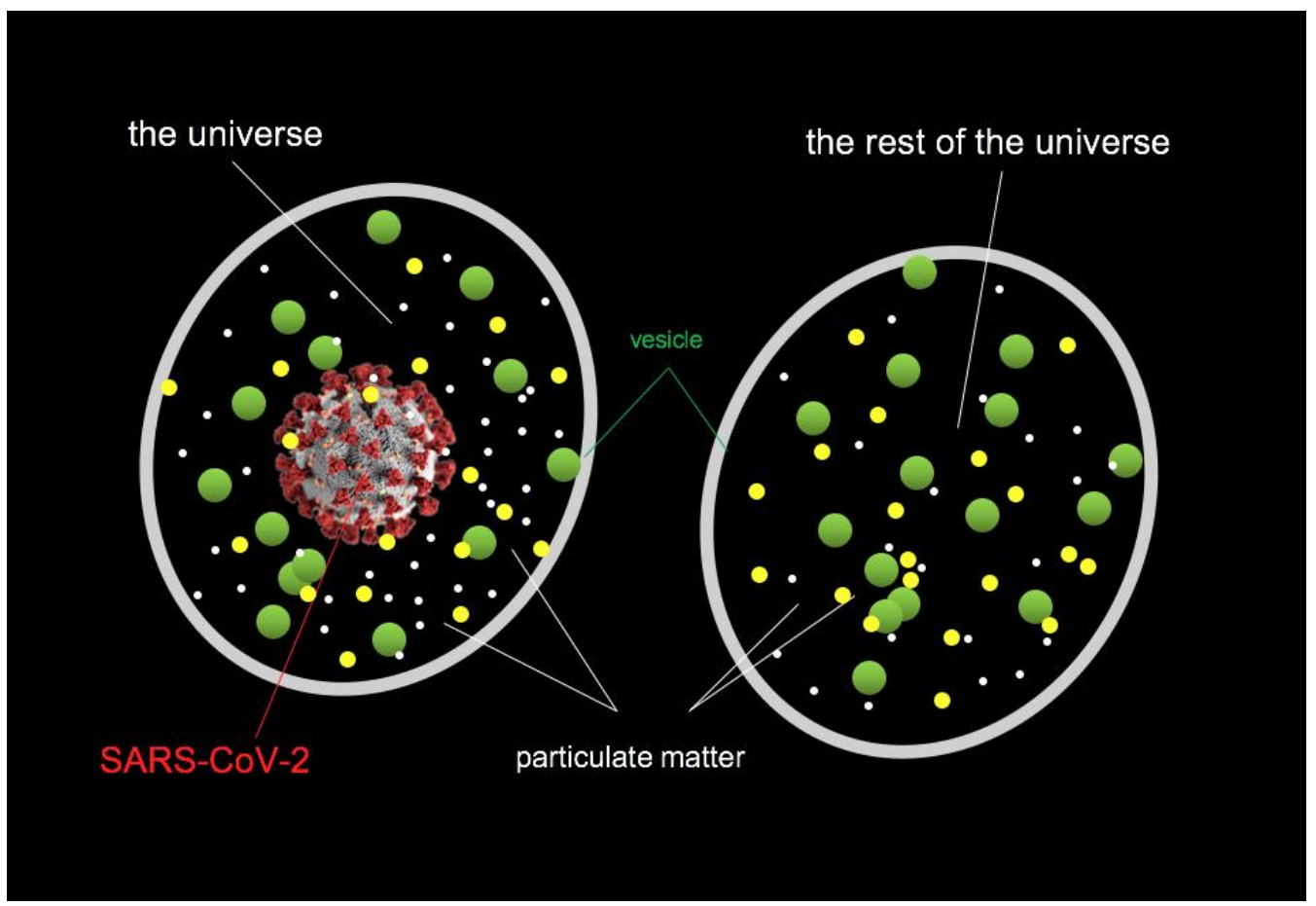

Fig. 9 SARS-CoV-2 with its environment inside a vesicle, as an isolated thermodynamic system. Universe (SARS-CoV-2 with its environment) and the rest of the universe (environment). Low UFP dust $0.025 \mu \mathrm{m}-0.100 \mu \mathrm{m}$ 


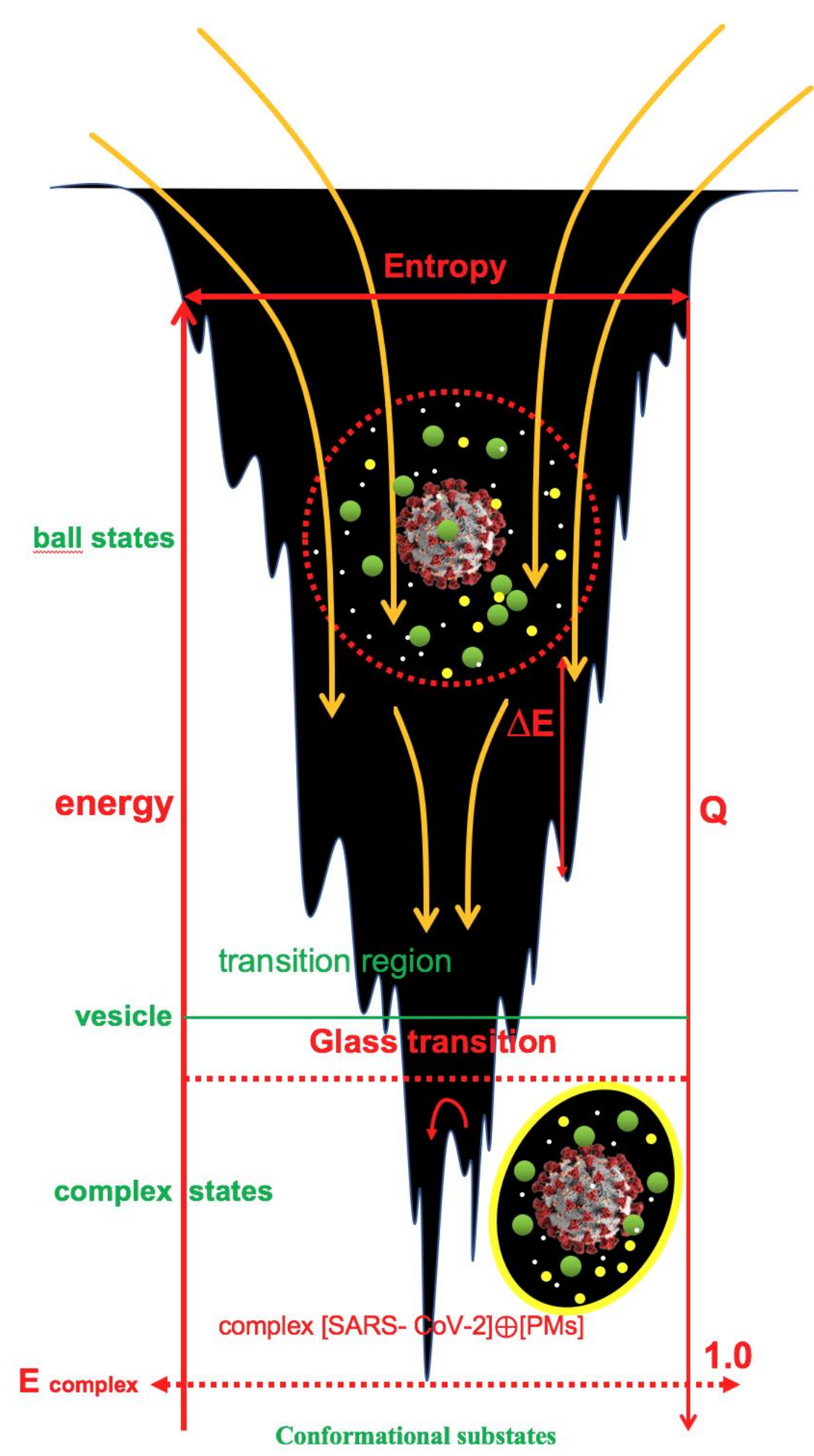

Fig. 10 Energy rugged funnel landscape for [SARS-CoV-2] $\oplus[\mathrm{PMs}]$ complex formation. 